\title{
ABSOLUTE AND RELATIVE BIOAVAILABILITY STUDY FOR THE NEWLY DEVELOPED NASAL NANOEMULSION IN SITU GEL OF ONDANSETRON HCI IN COMPARISON TO CONVENTIONALLY PREPARED IN SITU GEL AND INTRAVENOUS DOSAGES FORMS
}

\author{
NIDHAL K. MARAIEa, YASSER Q. ALMAJIDI ${ }^{b}$, AHMED ALSHADHER
}

aDepartment of Pharmaceutics, College of Pharmacy, Mustansiriyah University, Baghdad, Iraq, bDepartment of Pharmaceutics, Baghdad College of Medical Sciences, Baghdad, Iraq, 'The National Center for Drugs Control and Research, Baghdad, Iraq Email: pharm.dr.nidhal.khazaal@unomustansiriyah.edu.iq

Received: 18 May 2018, Revised and Accepted: 09 Jul 2018

\section{ABSTRACT}

Objective: The aim of the work was to study the absolute and relative bioavailability (using rabbits) of ondansetron $\mathrm{HCl}(\mathrm{ONH})$ from our newly prepared intranasal mucoadhesive nanoemulsion in situ gel (NIG) in comparison to intranasal mucoadhesive in situ gel (IG) prepared by the conventional method and intravenous injection.

Methods: Six male rabbits weighing 2.5-3 kg were used in this study, where the dose of ondansetron $\mathrm{HCl}(\mathrm{ONH})$ was calculated based on the body surface area (BSA) which is equivalent to $140 \mu$ (containing $10 \mathrm{mg} / \mathrm{ml}$ ) of NIG and IG and $700 \mu$ l of intravenous Zofran ${ }^{\circledR}$ injection (containing 2 $\mathrm{mg} / \mathrm{ml}$ ) were given to the rabbits, separated with one week washout period. Serial blood samples were withdrawn and analyzed for simultaneous determination of the drug using HPLC (Knaure; $150 \times 4.6 \mathrm{~mm} ; 5 \mu \mathrm{m}$ particle size; $25 \mathrm{~cm}$ length) supported by guard column C18-4 mm diameter.

Results: The pharmacokinetics parameters for NIG; Cmax, Tmax, AUC0-t, AUC0-œwere found to be greater than conventional in situ gel (IG). In vivo pharmacokinetic studies in rabbits showed a significant increase in $\mathrm{C}_{\max }$ and AUC ${ }_{0-\alpha}(\mathrm{P}<0.001)$ with shorter $\mathrm{T}_{\max }$ using NIG compared to IG containing the same NIG excipients, while the absolute bioavailability for NIG and IG (was 80.541 and 51.068 respectively).

Conclusion: The present studies ratify the bioavailability enhancement potential of NE used to prepare NIG for the drug and significantly high absolute bioavailability to be used as a successful alternative route to the IV injection and improve patient compliance.

Keywords: Bioavailability study, In situ gel, Nanoemulsion, NIG, Ondansetron $\mathrm{HCl}$

(C) 2018 The Authors. Published by Innovare Academic Sciences Pvt Ltd. This is an open-access article under the CC BY license (http://creativecommons.org/licenses/by/4.0/) DOI: http://dx.doi.org/10.22159/ijap.2018v10i5.27396

\section{INTRODUCTION}

Ondansetron $\mathrm{HCl}(\mathrm{ONH})$ is an antiemetic drug used as the first-line drug for the management of nausea and vomiting associated with cancer chemotherapy, chronic medical illness, gastroenteritis and post-operative states [1]. Oral ondansetron $\mathrm{HCl}(\mathrm{ONH})$ exhibits low bioavailability (i.e., $60 \%$ ) due to extensive hepatic oxidative metabolism $(95 \%)$ to form hydroxylated metabolites, which is mediated through multiple cytochrome $\mathrm{P} 450$ forms. The myriad drug delivery systems of ondansetron $\mathrm{HCl}(\mathrm{ONH})$ developed so far have yielded limited fruition in oral bioavailability enhancement [2].

Drugs administered through nasal route absorb rapidly and reach therapeutically effective plasma levels quickly due to the rich vasculature and highly permeable membranes in the nasal cavity [3]. Moreover, the nasal route offers an additional advantage over the oral route, particularly for those drugs that have poor oral bioavailability due to $\mathrm{pH}$ instability and enzyme degradation in the gastrointestinal tract (GIT). Further, drugs that undergo gut wall metabolism, P-glycoprotein efflux, and high hepatic first-pass metabolism are also benefited from nasal route of administration [4]. For a few drugs, plasma drug profiles from intranasal delivery are akin to that of intravenous drug profile of the same drug [5].

Recently, nanoemulsion (NE) is being seen as a carrier for intranasal delivery of drugs as it is more stable than other vesicular systems likes liposomes, ethosomes, niosomes, etc. They are translucent mixtures of oil, surfactant, cosurfactant, and water, in which either the oil globules are dispersed in water $(\mathrm{o} / \mathrm{w})$ or water globule are dispersed in oils (w/o). These systems are single, optically isotropic and thermodynamically stable with a droplet size typically in the range of 10-100 $\mathrm{nm}[6]$.

Due to low bioavailability of ondansetron $\mathrm{HCl}(\mathrm{ONH})$ and its inability to reach high concentration in plasma after oral administration, it was excogitated to develop a novel dosage form for ondansetron $\mathrm{HCl}$ $(\mathrm{ONH})$ that could address these problems through delivery of the drug into intranasal route to improve its bioavailability (by avoidance of first-pass metabolism).

However, owing to the anatomical and physiological conditions of the nasal cavity, intranasally administered drugs have low residence time at the site of administration. Rapid mucociliary clearance (MC) also limits the time available for drug absorption [4]. Therefore, in the design of intranasal formulations, one must address the problem of low residence time in the nasal cavity. Possible strategy to improve nasal residence time is to use formulations with higher viscosity, and preferably, with mucoadhesive character. Designing an intranasal dosage form with mucoadhesive character is particularly helpful because it provides intimate contact between dosage form and nasal epithelium thereby maximizing the chances of absorption for a drug molecule. Temperature sensitive in situ gel provide a suitable dosage form; they are easy to administer and have a suitable viscosity at body temperature to counter mucocilliary clearance (MC) [7].

In our previous studies; a mucoadhesive nasal in situ gel for $\mathrm{ONH}$ was prepared through the application of NE technology (NIG) where poloxamer 407 was used as thermo reversible polymer and chitosan and HPMC E15 were used as mucoadhesive polymers, NIG was evaluated in vitro and gave $100 \%$ release after $6 \mathrm{~h}$ with sharp burst effect. In addition, a nasal in situ gel (IG) containing the same contents of the nanoemulsion in situ gel(NIG) prepared by the conventional method and tested in vitro to show $60 \%$ release after 6 $\mathrm{h}[8,9]$.

This study involves the in vivo estimation (for the first time) of the contribution of nanoemulsion (NE) as a carrier for ondansetron $\mathrm{HCl}$ $(\mathrm{ONH})$ in our newly developed mucoadhesive intranasal in situ gel through studying the bioavailability of the drug relative to the intranasal in situ gel prepared by the conventional way (without carrier),as well as through comparing its bioavailability from these preparations to intravenous injection $\left(\operatorname{Zofran}^{\circledR}\right)$ of the drug 
(absolute bioavailability) to estimate its use as alternative dosage form than IV injection to be safe medicated and improve patient compliance.

\section{MATERIALS AND METHODS}

\section{Materials}

Ondansetron $\mathrm{HCl}$ [Hangzhou Hyper chemicals, China], HPMC E15, poloxamer407and chitosan [H-imedia Laboratories Pvt. Ltd. Mumbai, India], tween 20 [J. T Baker, China], acetonitrile and methanol absolute-HPLC grade [Biosolve B V, France], oleic acid [AlEmad company, Iraq]. Tetra-methyl-butyl ether-HPLC grade [Baoji Guokang Biotechnology Co, Ltd. China]. For all the experiments, deionized distilled water (DDW) was used.

\section{Methodology}

\section{Study design}

The protocol for the study was approved (approval number 205/2017) by animal care committee in the Iraqi national center for drugs control and researches. Briefly, six male, white rabbits weighing 2.5-3 kg were caught in rabbit hutch during blood samples collection. The rabbits were then positioned on a table supported in a horizontal position. The nasal and intravenous dose of rabbits were calculated, an equivalent amount of ondansetron $\mathrm{HCl}(\mathrm{ONH})$ were administrated to the animal. The calculation of animal nasal and intravenous (rabbit) doses was based on the body surface area (BSA) normalization method and the human equivalent dose (HED) of pharmaceuticals involving the species $(\mathrm{Km})$ factor (body weight in $\mathrm{kg}$ divided by BSA in $\mathrm{m}^{2}$ ) according to the following equation [10]:

$$
\mathrm{HED}(\mathrm{mg})=\text { Animal dose }(\mathrm{mg}) \times\left(\frac{\text { AnimalKm }}{\text { HumanKm }}\right) \text { Eq. } 1
$$

The recommended adult human single dose of ondansetron $\mathrm{HCl}$ $(\mathrm{ONH})$ per day is (three $0.15 \mathrm{mg} / \mathrm{kg}$ ), and the values of $\mathrm{Km}$ were 37 and 12 for adult human and rabbit respectively [11]. Hence, ondansetron $\mathrm{HCl}(\mathrm{ONH})$ dose for rabbit based on BSA normalization method was $1.4 \mathrm{mg}$. A micropipette tip (100-200 $\mu \mathrm{l}$ amplitude) layed $1 \mathrm{~cm}$ deep inside the right nostril of each rabbits, was used to administer $140 \mu$ l (containing $10 \mathrm{mg} / \mathrm{ml}$ ) of selected NIG formula and conventional intranasal in situ gel (IG). Intravenous administration of $700 \mu$ Z Zofran ${ }^{\circledR}$ injection $(2 \mathrm{mg} / \mathrm{ml})$ was given to the rabbits. Blood samples $(2 \mathrm{ml})$ were withdrawn from the marginal ear vein at zero time (first minute after administration) and $0.25,0.5,1.0,2.0,3.0$, 5.5, 7.5, 10 and $24 \mathrm{~h}$. Blood samples were centrifuged to collect plasma and collected in tubes containing EDTA and immediately frozen at $-20^{\circ} \mathrm{C}$ until analysis [12].

\section{Construction of calibration curve of OND-HCl in plasma by HPLC}

A stock solution of ondansetron $\mathrm{HCl}(\mathrm{ONH})(1 \mathrm{mg} / \mathrm{ml})$ was prepared by dissolving $10 \mathrm{mg}$ of ondansetron $\mathrm{HCl}(\mathrm{ONH})$ in $10 \mathrm{ml}$ methanol. Ondansetron $\mathrm{HCl}(\mathrm{ONH})$ working solutions were prepared by serial dilutions of the stock solution in methanol to obtain the final concentrations of (1-80 $\mu \mathrm{g} / \mathrm{ml})$. Calibration curves for ondansetron $\mathrm{HCl}(\mathrm{ONH})$ were prepared by spiking blank plasma with the working solutions (after evaporation of methanol) to get dilution (ten times) providing the definitive concentrations of $(100-8000 \mathrm{ng} / \mathrm{ml})$. The working plasma solutions of ondansetron $\mathrm{HCl}(\mathrm{ONH})$ were saved at 4 ${ }^{\circ} \mathrm{C}$ till use. The calibration curve was constructed by plotting area under the peak $(\mathrm{Y})$ versus ondansetron $\mathrm{HCl}(\mathrm{ONH})$ concentrations (X). A linear regression $\left(\mathrm{r}^{2}\right)$ method was used for quantification [13].

\section{Set up of plasma samples}

A $50 \mu \mathrm{l}$ portion of thawed rabbit plasma was presented into a glass tube at room temperature and $1.0 \mathrm{ml}$ of methyl tetra-butyl ether (MTBE) as the extraction solvent. After eddy blending for $20 \mathrm{~s}$, samples were centrifuged $(3500 \mathrm{rpm} / 3 \mathrm{~min})$ at $4{ }^{\circ} \mathrm{C}$ and transfer the organic phase to other clean glass tubes set then evaporation of the organic phase to get dry residues using nitrogen at $50^{\circ} \mathrm{C}$. A $500 \mu \mathrm{l}$ of acetonitrile-water $(50: 50, \mathrm{v} / \mathrm{v})$ was used to dissolve the dry residues, then eddy blending (10 s) for residue reconstitution [14]. The procedure was completed as mentioned under the construction of the calibration curve of ondansetron $\mathrm{HCl}(\mathrm{ONH})$ in plasma.

\section{Chromatographic conditions}

A $50 \mu \mathrm{l}$ of extracted samples were injected into a Knauer HPLC system (Germany) which consist of a Wellchrom K-1001 pump, a Rheodyne 7125 injector and a K 2501 UV detector with a thermostatic column compartment connected to a Eurochrom 2000 injector. A high-performance liquid chromatography was performed on an analytical C18 column (Knaure; $150 \times 4.6 \mathrm{~mm}$; $5 \mu \mathrm{m}$ particle size; $25 \mathrm{~cm}$ length) supported by guard column C18-4 mm diameter (Germany). The wavelength was set at $303 \mathrm{~nm}$. The mobile phase was acetonitrile-water (50:50, v/v) with $0.25 \mathrm{mmol}$ ammonium formate at a flow-rate of $0.80 \mathrm{ml} / \mathrm{min}$. Under these conditions, typical standard retention times were $3 \pm 0.5 \mathrm{~min}$ for ondansetron $\mathrm{HCl}(\mathrm{ONH})$. The autosampler was maintained at $4{ }^{\circ} \mathrm{C}$ and the total run time was $4.0 \mathrm{~min}[14,15]$.

\section{Pharmacokinetic parameters}

Non-compartmental pharmacokinetic analysis for ondansetron $\mathrm{HCl}$ $(\mathrm{ONH})$ was performed. The maximum plasma drug concentration $\left(\mathrm{C}_{\max }\right)$ and the time required to reach maximum plasma concentration $\left(\mathrm{T}_{\max }\right)$ after intravenous and nasal administration were directly determined from the plasma concentration-time curve. Also, the elimination rate constant (Ke), derived from the slope of the straight part of the terminal phase (where the slope equal to$\mathrm{Ke} / 2.303)$ [16], the elimination half-life time $\left(\mathrm{t}_{1 / 2}\right)$, derived from $0.693 / \mathrm{Ke}$ [19], the area under the plasma concentration-time curve from $0-24 \mathrm{~h}\left(\mathrm{AUC}_{0-24}\right.$ ) and the area under plasma concentrationtime curve from $0-\alpha\left(\mathrm{AUC}_{0-\alpha}\right)$ were calculated for each individual rabbit. The $\mathrm{AUC}_{0-24}$ was calculated using trapezoidal rule and extrapolation of the area to infinity $\left(\mathrm{AUC}_{0-\alpha}\right)$ was estimated by adding the last measured plasma concentration divided by the elimination rate constant (Ke) to $\mathrm{AUC}_{0-24}$ according to the following equation [17]:

$$
\mathrm{AUC}_{0-\alpha}=\frac{\mathrm{AUC}_{0-24}+\mathrm{C}_{24}}{\mathrm{Ke}} \mathrm{Eq} .2
$$

Where; $\mathrm{C}_{24}$ is the concentration of $\mathrm{ONH}$ after $24 \mathrm{~h}$. The absolute and relative bioavailability percent was calculated from the following equations, respectively [18]:

$$
\begin{aligned}
& \% \mathrm{~F}_{\text {absolute }} \ldots \ldots \ldots . . . . \% \mathrm{~F}=\frac{\mathrm{AUC}_{\text {test }}}{\mathrm{AUC}_{\mathrm{IV}}} \times \frac{\text { Dose }_{\mathrm{IV}}}{\text { Dose }_{\text {test }}} \times 100 \text { Eq. } 3 \\
& \% \mathrm{~F} \text { relative............ } \% \mathrm{~F}=\frac{\mathrm{AUC}_{\mathrm{IG}}}{\mathrm{AUC}_{\mathrm{NIG}}} \times \frac{\text { Dose }_{\mathrm{NIG}}}{\text { Dose }_{\mathrm{IG}}} \times 100 \text { Eq. } 4
\end{aligned}
$$

\section{Statistical analysis of bioavailability study}

Comparison between the pharmacokinetic parameters of ondansetron $\mathrm{HCl}(\mathrm{ONH})$ following the administration of marketed Zofran IV injection, prepared NIG and conventionally prepared IG formulations were carried out using one-way analysis of variance (ANOVA) followed by tukey-multiple comparison test. Statistical calculation was carried out using Graph Pad Prism 7.0 software.

\section{RESULTS AND DISCUSSION}

\section{Bioavailability study}

The concentration of ondansetron $\mathrm{HCl}(\mathrm{ONH})$ in rabbit's blood was determined using a reproducible, sensitive and rapid HPLC method. Fig. 1 showed peak chromatograms for ONH in standard solution and in a working plasma sample, the chromatographic conditions and extraction procedure yielded a clear chromatogram for analysis.

The retention time of ondansetron $\mathrm{HCl}(\mathrm{ONH})$ was detected in methanol and in plasma samples and was recorded to be $3 \pm 0.5 \mathrm{~min}$. The lower limit of detection of the drug in plasma by HPLC was measured by preparing different concentrations of ondansetron $\mathrm{HCl}$ $(100-8000 \mathrm{ng} / \mathrm{ml})$ in plasma and it was found to be $188.9 \mathrm{ng} / \mathrm{ml}$.

Fig. 2 showed the calibration curve of ondansetron $\mathrm{HCl}(\mathrm{ONH})$ in plasma. A straight line with high regression coefficient $\left(r^{2}=0.9995\right)$ was obtained by plotting the area under the peak versus the concentration (in the plasma working range $100-8000 \mathrm{ng} / \mathrm{ml}$ ), this indicates that the calibration curve obey Beer's law within the range of concentration used. 


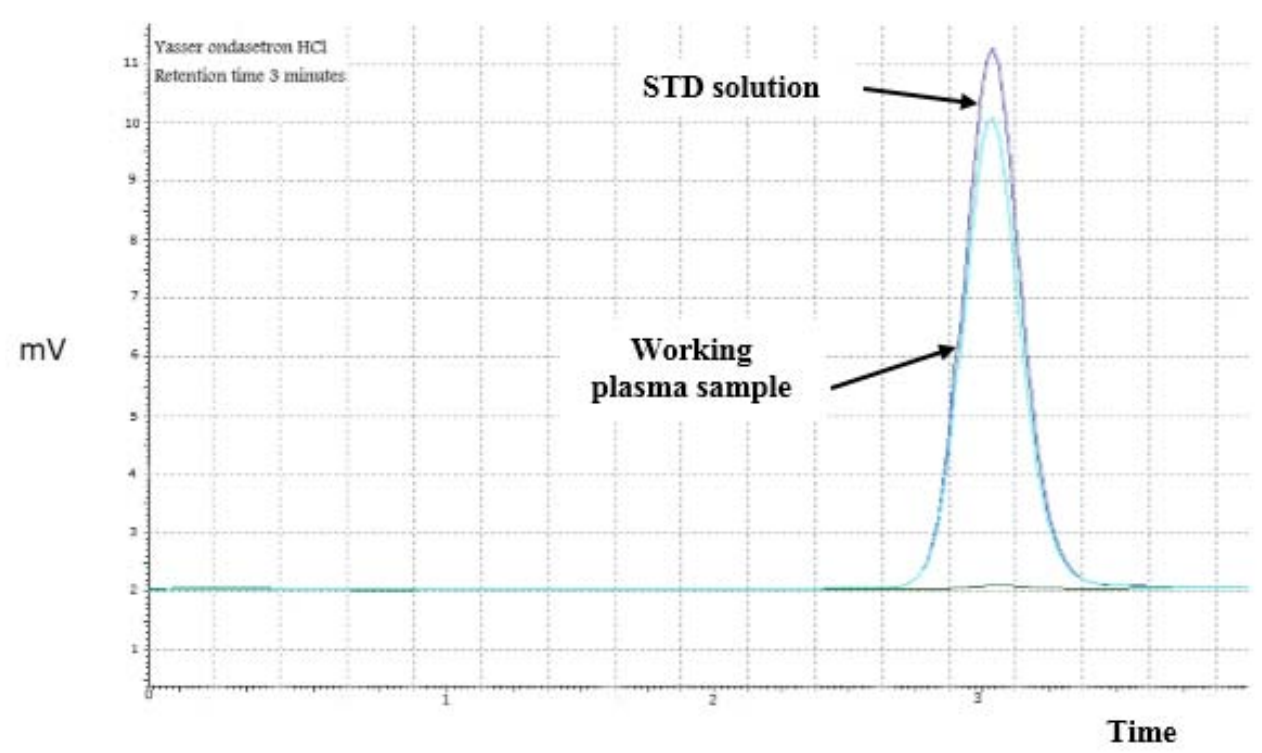

Fig. 1: Representative HPLC chromatograms of standard solution (STD) and working plasma sample of ondansetron HCl (ONH)

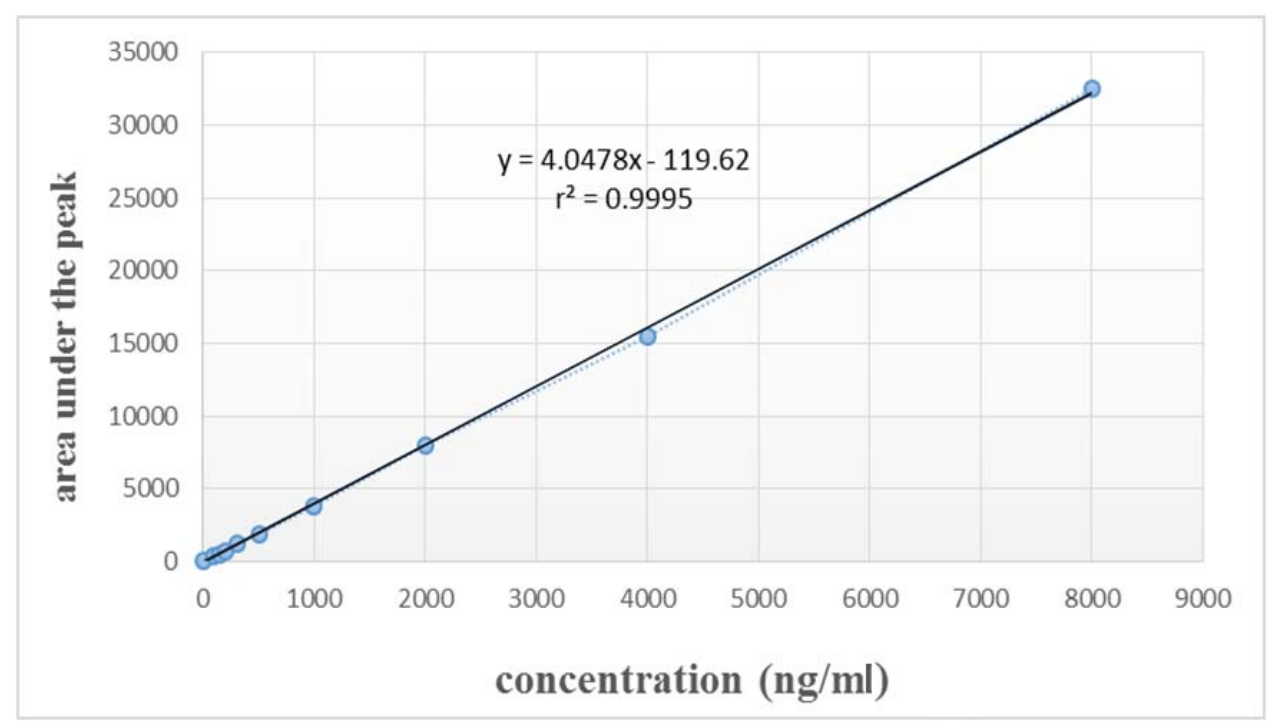

Fig. 2: Calibration curve of ondansetron $\mathrm{HCl}(\mathrm{ONH})$ in plasma by HPLC

Fig. 3 depicts the mean plasma concentration profile as a function of time for the optimized nanoemulsion in situ gel (NIG) in comparison to prepared conventional in situ gel (IG) and in comparison to marketed IV injection (Zofran $®$ ) by using crossover design with one week washout period. The mean blood concentration versus time profile revealed that first order pharmacokinetic model without lag time and first-order elimination rate was considered to be the best fit to explain the generated data, where the drug concentration in plasma after administration of the dose and progressing of analysis, the concentration increased until reached the peak level $\left(\mathrm{C}_{\max }\right)$. After the peak level of the drug was reached, the plasma level of the drug decreased indicating that the rate of elimination from plasma stream is greater than the rate of absorption(absorption process does not terminate).

Table 1 illustrated the arithmetic mean and standard deviation values of plasma drug concentration $(\mathrm{ng} / \mathrm{ml})$ of ondansetron $\mathrm{HCl}$ $(\mathrm{ONH})$ at the selected time intervals for 6 rabbits having different weights (2.5-3 kg) and receiving single dose of ONH (1.4 mg) of the prepared nanoemulsion in situ gel (NIG), conventional prepared in situ gel (IG) and commercial Zofran $®$ injection with one week washing period between them.
Table 2 shows the pharmacokinetic parameters for ondansetron $\mathrm{HCl}$ $(\mathrm{ONH})$ in the prepared nanoemulsion in situ gel (NIG), conventional prepared in situ gel (IG) and marketed IV injection. From these results, it was evident that, the absorption of ondansetron $\mathrm{HCl}$ (ONH) from the nanoemulsion in situ gel (NIG) reached its peak plasma concentration in $2 \mathrm{~h}$, the mean $\mathrm{T}_{\max }$ of marketed Zofran IV injection was $0 \mathrm{~h}$ (the drug directly inside the blood circulation without absorption) while, for the conventionally prepared in situ gel (IG), the $\mathrm{T}_{\max }$ was $3 \mathrm{~h}$. Also, it was found that the absolute bioavailability ( $F_{\text {absolute}}$ ) for nanoemulsion in situ gel (NIG) $(80.541 \%)$ was significantly higher $(\mathrm{P}<0.001)$ than that for conventional in situ gel (IG) $(51.068 \%)$. These findings ensure the goal of contribution of nanoemulsion technology applied for the situ gel preparation in NIG which showed higher and rapid absorption than conventional in situ gel(IG) formula, estimated by increasing the mean maximum plasma drug concentration $\left(\mathrm{C}_{\max }\right)$ and reducing the time required to reach maximum plasma drug concentration $\left(\mathrm{T}_{\max }\right)$, increasing the total amount of ondansetron $\mathrm{HCl}$ $(\mathrm{ONH})$ present in blood for longer time as indicated by the high value of $\mathrm{AUC}_{0-\alpha}$ and finally, this in vivo study is inconsistent with the vitro release of the drug from both formulas nanoemulsion in situ gel 
(NIG) and conventional in situ gel (IG)(where the drug gave 100\% in vitro release after $6 \mathrm{~h}$, while $60 \%$ in vitro drug release after $6 \mathrm{~h}$ from conventional IG), indicating that nanoemulsion technology used in NIG improved the bioavailability of the drug (80.541\%) through improving its release and permeability through nasal cavity[9]. In comparison to the reported work for the same drug but is prepared as intranasal surface engineered nanostructural lipid carrier showed absolute bioavailability (68.24\%) which is less than that of nanoemulsion in situ gel (NIG) [19]. Also, NIG exceeds the absolute bioavailability of oral tablet and oral solution (65\% and $71 \%$ respectively) [20].
The nanoemulsion in situ gel (NIG) formula remains in the nose of the experimented rabbit till the end of the study indicating good mucoadhesive property of the preparation without drainage or detachment during the experimental time. Therefore, this study showed that in situ gel nasal preparation prepared by applying nanoemulsion technology (NIG) which is liquid at room temperature and upon instillation into the nose, it will change to a gel as an acceptable alternative dosage form (to IV) with effective, safe, good bioavailability, less frequent doses (improves patient compliance) and better result than the in situ gel prepared by conventional method (IG).

Table 1: Mean plasma concentration $(\mathrm{ng} / \mathrm{ml})$ of ondansetron $\mathrm{HCl}(\mathrm{ONH})$ at the time intervals following administration of single dose of the prepared nanoemulsion in situ gel (NIG), conventionally prepared in situ gel (IG) and the marketed Zofran ${ }^{\circledR}$ IV injection

\begin{tabular}{llll}
\hline Time (h) & \multicolumn{2}{l}{ Mean plasma drug concentration (ng/ml) } & IG \\
\cline { 2 - 4 } & IV & NIG & $200.91 \pm 28.05$ \\
\hline 0.01 & $7000 \pm 141.80$ & $780.93 \pm 48.5$ & $381.96 \pm 42$ \\
0.25 & $6850.84 \pm 71$ & $1299.5 \pm 22.38$ & $521.22 \pm 57.72$ \\
0.5 & $6482.38 \pm 49.99$ & $1644.8 \pm 12.34$ & $807.27 \pm 78$ \\
1 & $5992.72 \pm 92.14$ & $2443.1 \pm 49.2$ & $1827.44 \pm 49$ \\
2 & $5189.48 \pm 71.17$ & $3865.25 \pm 63$ & $2885.6 \pm 49.31$ \\
3 & $4371.01 \pm 64.69$ & $3633 \pm 53.9$ & $1918.06 \pm 42.68$ \\
5.5 & $3257.87 \pm 57.02$ & $2890 \pm 82.12$ & $1489.52 \pm 57.98$ \\
7.5 & $2465.86 \pm 14.83$ & $2375 \pm 93$ & $1025.78 \pm 49.57$ \\
10 & $1700.44 \pm 92$ & $1650 \pm 129.7$ & $188.9 \pm 49$ \\
\hline
\end{tabular}

$\mathrm{n}=6($ mean $\pm \mathrm{SD})$

Table 2: Pharmacokinetics parameters of a single dose of ondansetron $\mathrm{HCl}(\mathrm{ONH})$ from the optimized nanoemulsion in situ gel (NIG), optimized in situ gel (IG) formula and the commercial Zofran ${ }^{\circledR}$ IV injection

\begin{tabular}{|c|c|c|c|c|}
\hline The mean pharmacokinetic parameters & IV ( \pm SD) & NIG ( \pm SD) & IG (土SD) & $P^{(3)}$ value \\
\hline $\mathrm{t}_{\max }(\mathrm{h})$ & $0 \pm 0.0$ & $2 \pm 0.0$ & $3 \pm 0.0$ & $\mathrm{P}<0.001$ \\
\hline $\mathrm{C}_{\max }(\mathrm{ng} / \mathrm{ml})$ & $7000 \pm 141.80$ & $3865.25 \pm 57$ & $2885.6 \pm 49.31$ & $\mathrm{P}<0.001$ \\
\hline $\operatorname{AUC}_{1 \rightarrow 24}(\mathrm{ng} / \mathrm{ml} . \mathrm{h})$ & $50816.412 \pm 19.9$ & $40698.219 \pm 38.0$ & $25250.765 \pm 22.9$ & $P<0.001$ \\
\hline $\mathrm{AUC}_{1 \rightarrow \alpha}\left(\% \mathrm{CV}^{(1)}\right)(\mathrm{ng} / \mathrm{ml} . \mathrm{h})$ & $52428.731(7.51 \%)$ & $45165.610(5.59 \%)$ & $26774.152(2.17 \%)$ & $P<0.001$ \\
\hline $\mathrm{K}_{\mathrm{e}} \pm \operatorname{SEM}^{(2)}\left(\mathrm{h}^{-1}\right)$ & $0.138 \pm 0.020$ & $0.092 \pm 0.041$ & $0.124 \pm 0.040$ & $P<0.001$ \\
\hline$t_{1 / 2}(h)$ & 5.022 & 7.533 & 5.589 & $\mathrm{P}<0.001$ \\
\hline$\% \mathrm{~F}_{\text {(absolute) }}$ & - & 86.147 & 51.068 & $\mathrm{P}<0.001$ \\
\hline$\% \mathrm{~F}_{\text {(relative) }}(\mathrm{IG} / \mathrm{NIG})$ & - & - & 59.28 & - \\
\hline
\end{tabular}

$\mathrm{n}=6$ (mean $\pm \mathrm{SD}$, (1) CV\% = Percent coefficient of variation. (2) SEM = Standard error mean, (3) P = Probability value

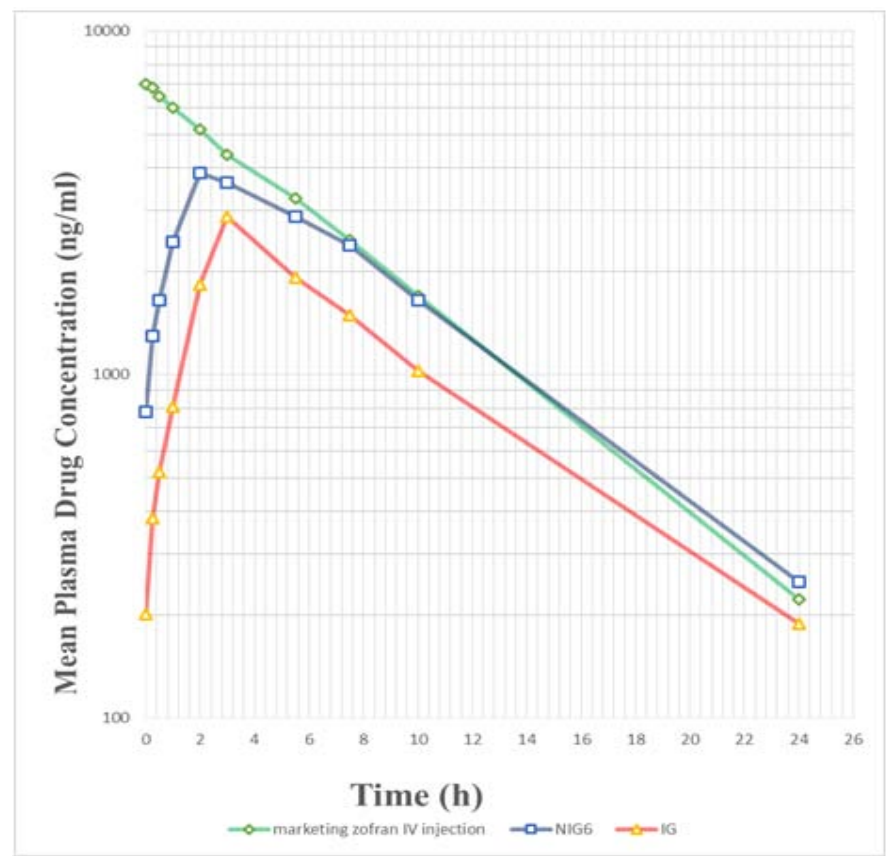

Fig. 3: Mean plasma drug concentration profile versus time obtained during the in vivo pharmacokinetic studies carried out in six rabbits receiving single dose of the prepared nanoemulsion in situ g00el (NIG), conventional prepared in situ gel (IG) and marketed (Zofran ${ }^{\circledR}$ ) IV injection 


\section{CONCLUSION}

This work describes a fast, sensitive and robust method to quantify ondansetron $\mathrm{HCl}(\mathrm{ONH})$ in rabbit plasma using HPLC. The described method for $\mathrm{ONH}$ quantification in rabbit plasma was successfully applied in a bioequivalence study of the prepared nanoemulsion in situ gel(NIG), conventionally prepared in situ gel(IG) and marketed Zofran IV injection using an open, randomized, two-period crossover design with a $7 \mathrm{~d}$ washout period between doses. Since the prepared NIG formula showed high absolute bioavailability suggesting it as a good alternative candidate for IV injection that will improve patient compliance. The work also proved the role of nano-sized droplets in the in situ gel nasal prepared using nanoemulsion technology in improving the absorption rate and extent of the drug in comparison to conventionally prepared in situ gel preparation.

\section{ACKNOWLEDGMENT}

The authors would like to thank Mustansiriyah University (www. uomustansiriyah. edu. iq) Baghdad-Iraq for its support in the present work. Special thanks to Dr. Sabah jawed in Iraqi national center for drug control and research for this help.

\section{AUTHORS CONTRIBUTIONS}

All the author have contributed equally

\section{CONFLICT OF INTERESTS}

Declared none

\section{REFERENCES}

1. USP DI. The United States Pharmacopoeial convention Inc. 15th edn. Rockville, MD; 1995. p. 2062-3.

2. Menaka M, Pandey VP, Smith AA. Colloidal dispersions as a potential nasal drug delivery system forondansetron hydrochloride-in vitro and in vivo properties. Asian J Pharm Clin Res 2014;7:72-5.

3. Srivastava R, Srivastava S, Singh SP. Thermoreversible in-situ nasal gel formulations and their pharmaceutical evaluation for the treatment of allergic rhinitis containing extracts of Moringa olifera and Embelia ribes. Int J Appl Pharm 2017;9:16-20.

4. Ugwoke MI, Verbeke N, Kinget R. The biopharmaceutical aspects of nasal mucoadhesive drug delivery. J Pharm Pharmacol 2001;53:3-21.

5. Romeo VD, deMeireles J, Sileno AP. Effects of physicochemical properties and other factors on systemic, nasal drug delivery. Adv Delivery Rev 1998;29:89-116.
6. Shafiq A. Design and development of oral oil in water ramipril nanoemulsion formulation. In vitro and in vivo assessment. J Biomed Nanotech 2007;3:280-44.

7. Ugwoke MI, Verbeke N, Kinget R. Nasal mucoadhesive drug delivery: background, application, trends and future perspectives. Adv Drug Delivery Rev 2005;57:1640-65.

8. Maraie NK, Almajidi YQ. Effect of different mucoadhesive polymers on the release of ondansetron $\mathrm{HCl}$ from intranasal mucoadhesive in situ gel. Afr J Plant Sci 2017;17:76-85.

9. Maraie NK, Almajidi YQ. Application of nanoemulsion technology for preparation and evaluation of intranasal mucoadhesive nano-in situ gel for ondansetron $\mathrm{HCl}$. J Global Pharma Technol 2018;10:431-42.

10. Shaw SR, Nihal M, Ahmad N. Dose translation from animal to human studies revisited. FASEBj 2007;22:659-61.

11. Glaxo Smith Kline. Zofran (ondansetron hydrochloride) injection prescribing information. Research Triangle Park. NC; 2012.

12. Ponnuri RNL, Pragallapati P, Ravindra N, Mandava VBR. A rapid and sensitive liquid chromatography-mass spectrometry/mass spectrometry method for estimation of pioglitazone, keto pioglitazone and hydroxy pioglitazone in human plasma. Asian J Pharm Clin Res 2017;10:120-8.

13. Owayez AS, Abd El-ghany GM, Abu Hashim. Pharmaceutical studies on formulation and evaluation of sustained release tablets containing certain drugs. M. Sc. thesis, Mansoura University; 2017. p. 107.

14. Moreira RF. Development and validation of a rapid and sensitive LC-ESI-MS/MS method for ondansetron quantification in human plasma and its application in comparative bioavailability study. Biomed Chromatogr 2010;24:1220-7.

15. Tewthanom $K$, Jongjaroenprasert $W$. The pharmacokinetics of 2 doses (50 mg and $100 \mathrm{mg}$ ) levothyroxine treatment in athyreotic patients. Int J Appl Pharm 2016;8:66-8.

16. Bauer LA. Applied clinical pharmacokinetic. Seconded. USA: McGraw-hills; 2008. p. 21-3.

17. Gibaldi M. Biopharmaceutics and clinical pharmacokinetics. Fourth ed. Lea and Febiger: Malvem, PA; 1991. p. 23-8.

18. Shargel L, pong SW, yu ABC. Applied biopharmaceutical and pharmacokinetics. Fifth ed. USA: McGraw-hills; 2004. p. 56-8.

19. Devkar TB, Tekade AR, Khandelwal KR. Surface engineered nanostructured lipid carriers for efficient nose to brain delivery of ondansetron $\mathrm{HCl}$ using delonix regia gum as a natural mucoadhesive polymer. Colloids Surf B 2014:122:143-50.

20. Vandenberg CM, Kazmi Y, Stewart J, Weidler DJ, Tenjarla SN, Earl S. et al. Pharmacokinetics of three formulations of ondansetron hydrochloride in healthy volunteers: 24-Mg oral tablet, rectal suppository, and IV. Infusion. Am J Hosp Pharm 2000;57:45-8. 